\title{
EFFECT OF WELD CONVEXITY SIZES ON STRESS STATE OF BUTT JOINT DURING TENSION
}

\author{
G.V. ERMOLAEV, V.A. MARTYNENKO and I.V. MARUNICH \\ Admiral Makarov National Shipbuilding University \\ 9 Geroev Stalingrada Ave., 54025, Nikolaev, Ukraine. E-mail: welding@nuos.edu.ua
}

\begin{abstract}
To find out the possibility of compensation of decreased strength of weld metal by increase in sizes of convexity of butt joint and establishment of dependence of required height of convexity on strength ratio of weld and base metal, the investigation of level and nature of distribution of stresses in butt joints at their tension loading using different sizes of convexities was carried out. The investigations were made by the method of computer modeling on butt joints of C25 and C21 types. Height and width of convexity were varied at constant thickness of base metal. Convexity shape was taken in the form of arc. Fields of all components of stresses, and also their diagrams in different sections of weld were studied. The obtained values of coefficients of concentration (1.8-2.3) in varying the sizes of convexity within the rather wide ranges confirmed the adequacy of modeling. At the same time it was shown that the presence of convexity in symmetric joint of C25 type decreases somewhat the level of maximum tensile and equivalent stresses inside the weld metal, that gives possibility to compensate its strength as compared with base metal, but this decrease is non-proportional to the increase of section area. The expression was obtained, which allows calculating the required value of convexity in joint of C25 type at a known degree of decrease in strength of deposited metal as compared with base metal. The presence of convexities and their size in non-symmetric joint of $\mathrm{C} 21$ type does not almost influence the level of maximum equivalent stresses in section along weld axis, therefore it is impossible to compensate the decreased strength of weld metal by increase of convexities in such joint. The obtained results can be used in design of butt joints of materials, in particular high-strength steel joints made by austenitic materials, which encounter problem in providing equal strength of weld and base metal. 12 Ref., 4 Tables, 7 Figures.
\end{abstract} Ke $\boldsymbol{y}$ word $\boldsymbol{s}:$ butt joint, distribution of stresses, con-
vexity sizes, static loading

Classic shape of transverse section of butt joint, made by arc methods of welding, assumes the presence of weld convexity, whose sizes are regulated by all the standards for welded joints [1-3]. Long time this convexity was called a weld reinforcement as it was supposed that the increase in metal thickness in weld axis can compensate the possible decrease in its strength as compared to base metal.

With development and improvement of welding technology and welding consumables, the producing of weld metal, fully equal to base metal for the majority of materials used in welded structures, is not a problem any more. Respectively, the requirements to weld convexity sizes in most cases remained purely symbolic. In present effective interstate standards (GOST) the height of convexity has been established for all the thicknesses within the interval from 1.5 up to $4 \mathrm{~mm}$ at width from 5-6 up to $60 \mathrm{~mm}$ [1-3].

However, for some materials, for instance high-strength steels, the problem of producing welds of strength fully equal to that of base metal remains actual also at the present time. If it is not possible to produce the full-strength weld metal, for example, in applying of welding consumables of austenitic class, it is necessary to decrease the admissible load or stresses in it due to increase of the convexity height. It is the latter that is envisaged by appropriate technical requirements to welded butt joints of high-strength steels used in construction of hulls of military ships and submarines. But in this case another problem arises: concentration of stresses in site of transition from base to weld metal. That is why in the present effective standards for welding terminology the term «reinforcement» is referred to inadmissible and replaced by term «convexity» $[4,5]$.

Analysis of stressed state of joint in loading by tension using methods of theory of elasticity $[6,7]$ showed that in the presence of convexity in the weld zone the uniformity of distribution is violated, maximum stresses in site of concentration (transition from base to deposited metal) exceed the average ones by 1.6 up to 2 and more times. At the same time the majority of structure elements of high-strength steels, for example, lining of hulls of above-water ships and submarines are designed for strength at static axial loading. As the experimental investigations showed during loading by static load and sufficient plasticity 
Table 1. Variants of investigated models of joints of C25 type

\begin{tabular}{|c|c|c|c|c|c|c|}
\hline $\begin{array}{l}\text { Number of } \\
\text { variant }\end{array}$ & $\begin{array}{l}\text { Height of convexity } \\
\qquad a, \mathrm{~mm}\end{array}$ & $\begin{array}{l}\text { Width of convexity } \\
\qquad b, \mathrm{~mm}\end{array}$ & Relative height $a / b$ & Relative width $b / s$ & $\begin{array}{l}\text { Full section } \\
s+2 a\end{array}$ & $\begin{array}{l}\text { Coefficient of } \\
\text { reinforcement } K_{\mathrm{r}} \\
\quad(s+2 a) / s\end{array}$ \\
\hline 1 & 2.5 & 23 & 0.11 & 0.77 & 35 & 1.17 \\
\hline 2 & 4.5 & 43 & 0.10 & 1.43 & 39 & 1.30 \\
\hline 3 & 7.5 & 73 & 0.10 & 2.43 & 45 & 1.50 \\
\hline 4 & 2.5 & 25 & 0.10 & 0.83 & 35 & 1.17 \\
\hline 5 & 4.5 & 45 & 0.10 & 1.50 & 39 & 1.30 \\
\hline 6 & 7.5 & 75 & 0.10 & 2.50 & 45 & 1.50 \\
\hline 7 & 2.5 & 29 & 0.09 & 0.97 & 35 & 1.17 \\
\hline 8 & 4.5 & 49 & 0.09 & 1.63 & 39 & 1.30 \\
\hline 9 & 7.5 & 79 & 0.10 & 2.63 & 45 & 1.50 \\
\hline 10 & 10 & 120 & 0.11 & 4 & 50 & 1.67 \\
\hline
\end{tabular}

Table 2. Variants of investigated models of joints of C21 type

\begin{tabular}{|c|c|c|c|c|c|c|c|c|c|c|}
\hline $\begin{array}{c}\text { Number of } \\
\text { variant }\end{array}$ & $\begin{array}{c}\text { Height of } \\
\text { convexity } \\
a, \mathrm{~mm}\end{array}$ & $\begin{array}{c}\text { Width of } \\
\text { convexity } b \\
\text { mm }\end{array}$ & $\begin{array}{c}\text { Relative } \\
\text { height } a / b\end{array}$ & $\begin{array}{c}\text { Relative } \\
\text { width } b / s\end{array}$ & $\begin{array}{c}\text { Height of } \\
\text { convexity } \\
a_{1}, \mathrm{~mm}\end{array}$ & $\begin{array}{l}\text { Width of } \\
\text { convexity } \\
b_{1}, \mathrm{~mm}\end{array}$ & $\begin{array}{c}\text { Relative } \\
\text { height } a_{1} / b_{1}\end{array}$ & $\begin{array}{l}\text { Relative } \\
\text { width } \\
b_{1} / s_{1}\end{array}$ & $\begin{array}{l}\text { Full section } \\
\mathrm{s}+a+a_{1}\end{array}$ & $\begin{array}{l}\text { Coefficient } \\
\text { of rein- } \\
\text { forcement } K_{\mathrm{r}} \\
\quad(s+a+ \\
\left.+a_{1}\right) / s\end{array}$ \\
\hline 11 & 2.5 & 23 & 0.11 & 0.77 & 0.83 & 7.6 & 0.11 & 0.25 & 33 & 1.11 \\
\hline 12 & 4.5 & 43 & 0.10 & 1.43 & 1.50 & 14.3 & 0.10 & 0.48 & 36 & 1.20 \\
\hline 13 & 7.5 & 73 & 0.10 & 2.43 & 2.50 & 24.3 & 0.10 & 0.81 & 40 & 1.33 \\
\hline 14 & 2.5 & 25 & 0.10 & 0.83 & 0.83 & 8.3 & 0.10 & 0.28 & 33 & 1.11 \\
\hline 15 & 4.5 & 45 & 0.10 & 1.50 & 1.50 & 15 & 0.10 & 0.50 & 36 & 1.20 \\
\hline 16 & 7.5 & 75 & 0.10 & 2.50 & 2.50 & 25 & 0.10 & 0.83 & 40 & 1.33 \\
\hline 17 & 2.5 & 29 & 0.09 & 0.97 & 0.83 & 9.6 & 0.09 & 0.32 & 33 & 1.11 \\
\hline 18 & 4.5 & 49 & 0.09 & 1.63 & 1.50 & 16.3 & 0.09 & 0.54 & 36 & 1.20 \\
\hline 19 & 7.5 & 79 & 0.10 & 2.63 & 2.50 & 26.3 & 0.10 & 0.88 & 40 & 1.33 \\
\hline
\end{tabular}

of metal, this concentration as well as residual welding stresses do not influence the strength of welded joint as a whole. From this point of view the use of convexity (reinforcement) for increasing the load-carrying capacity of butt joint at static loading is quite possible.

The known recent works are devoted to determination of degree of stress concentration in the site of transition from deposited to base metal [8-10] and effect of concentration on strength of welded joints [11, 12]. Unfortunately, there are no almost data on stressed state of deposited metal (weld metal) as a whole and, as a consequence, the quantitative relations, which allow determining the convexity sizes, are necessary for compensation of decrease in characteristics of weld metal strength. Therefore, the subject of the present work is urgent.

The aim of the present work is the establishment of dependence of level and nature of distribution of stresses on convexity sizes, study of possibility of compensation of weld metal decreased strength by increase in convexity sizes.

The investigations were carried out by the method of computer modeling using licensed pro- gram complex ANSYS (vers. 10). Plane-strain problems were solved using finite elements method (FEM) PLANE 182. The butt joints of C25 type (symmetric, with $\mathrm{X}$-shaped edge groove) and C21 (nonsymmetric, with V-shaped edge groove) of thickness $s=30 \mathrm{~mm}$ were investigated. Height and width of convexity were varied (Table 1). Shape of convexity was taken in the form of arc.

Due to symmetry of joint C25 with respect to horizontal $x$ and vertical $y$ axes, FE-model was plotted for the upper right quarter of physical model at a proper fixation of units on axes $x$ and $y$ (Figure 1). In joint C21, symmetrical only with respect to axis $y$, the model was plotted for the right half at a proper fixation of units on axis $y$.

Size along axis $x$ was selected so that the distribution of stresses near the edges was close to uniform that eliminated the effect of these areas on stressed state in the weld zone.

The elastic problem was solved. Physico-mechanical properties were taken the same as for the steel: elasticity modulus $E=2 \cdot 10^{5} \mathrm{MPa}$, Poisson coefficient $\mu=0.3$. 


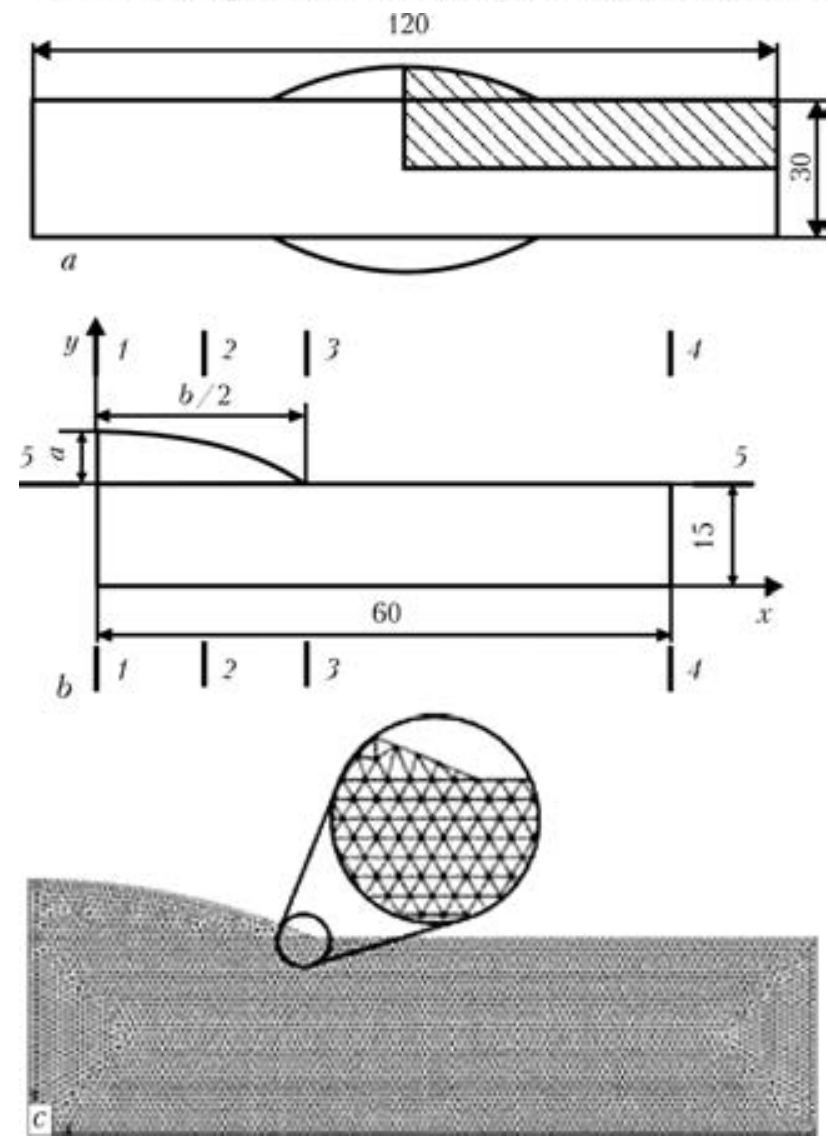

Figure 1. General view of physical $(a)$, calculation $(b)$ and FE (c) models of joint C25 (see description 1-5 in the text)

Models were loaded by uniformly distributed tensile forces on edges, generating the stresses $\sigma_{x}=100 \mathrm{MPa}$ on them.

Fields of longitudinal and transverse, tangent and equivalent (by Mises) stresses as well as their diagrams in sections on weld axis (1), at the distance $b / 4$ or $b_{1} / 2$ from axis $y$ in joints C25 and C21, respectively (2), along convexity edge (3), on node edge (4) and along upper and lower edges of models $(5,6)$ were studied $(\mathrm{Fi}-$ gures $1, b$ and $2, b$ ).

Analysis of fields (Figures 3 and 4) showed that their nature in changing the sizes of convexities is little changed as a whole. Near the sites of concentration (transition from deposited metal to base one), the transverse and tangent stresses are appeared. In addition, small transverse and tangent stresses occur in the inner part of the deposited metal. Metal in convexities is noticeably unloaded.

Nature of distribution of longitudinal and equivalent stresses is little differed. On the weld axis (section 1) of joint C25 these stresses are maximum in the middle part, where they somewhat exceed the average level, and they are gradually decreased with approach to convexities (Figure 5). Due to appearance of transverse and tangent stresses the level of equivalent stresses is somewhat differed from longitudinal ones.

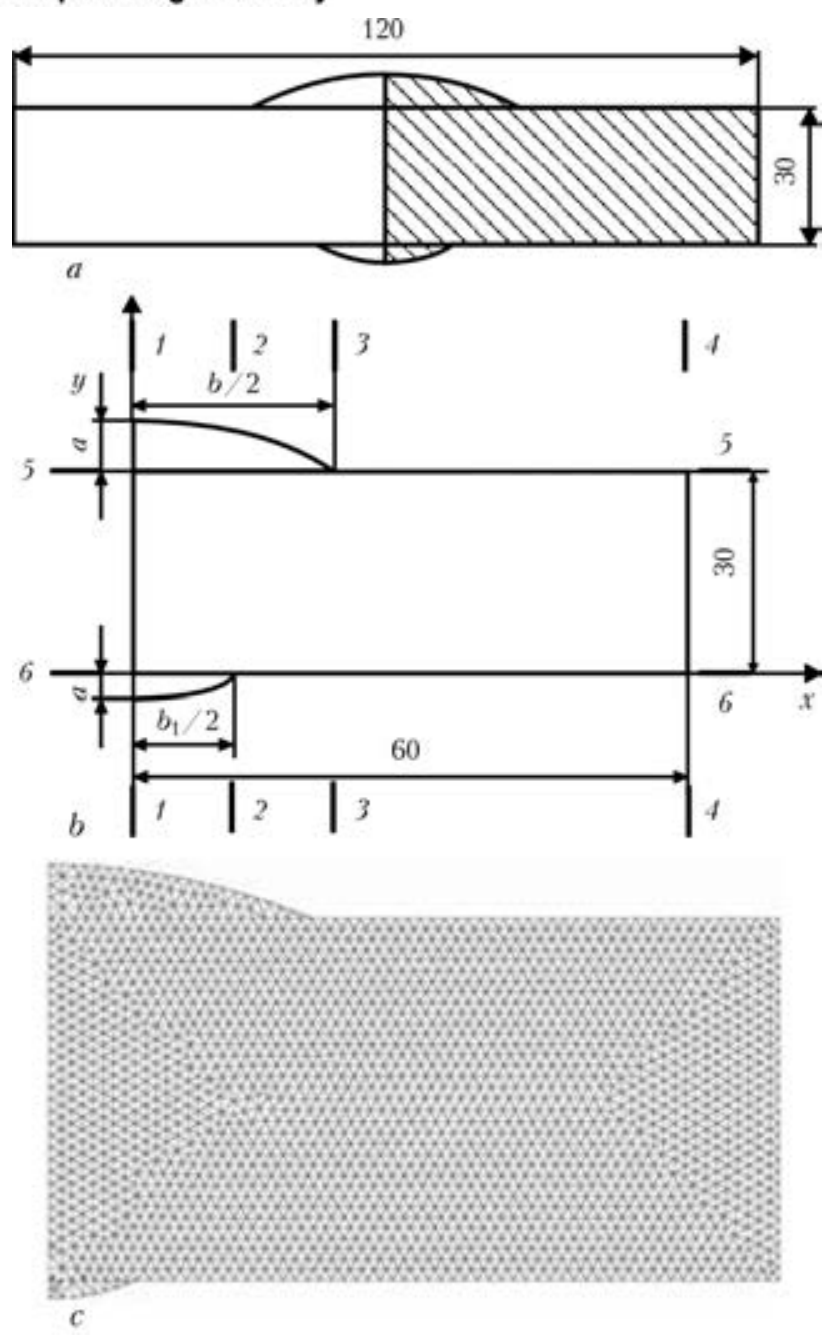

Figure 2. General view of physical $(a)$, calculation $(b)$ and $\mathrm{FE}(c)$ models of joint C21 (see description 1-6 in the text)

At the distance of convexity width quarter (section 2) the nature of distribution and level of stresses is retained. In site of concentration of stresses (section 3) all the stresses are abruptly growing. Sizes of convexity have small effect on nature of diagrams of stresses, somewhat changing their level (see Figure 5).

In joint $\mathrm{C} 21$ the nature of distribution of stresses in the upper half of joint is retained as a whole, but their level is somewhat decreased as a result of model bending due to its asymmetry relative to longitudinal axis (Figure 6). In the lower part in this case the bending decreases the degree of loading in the convexity region (section 1) and increases the degree of concentration in the site of transition from base to deposited metal (section 2).

For convenience of quantitative estimation of level of stresses, Tables 3 and 4 give values of maximum $\left(\sigma_{\max 1}, \quad \sigma_{\max 2}, \sigma_{\max 3}\right)$, minimum $\left(\sigma_{\mathrm{min} 3}\right)$ and average $\left(\sigma_{\mathrm{av} 1}, \sigma_{\mathrm{av} 2}, \sigma_{\mathrm{av} 3}\right)$ equivalent stresses in sections $1-3$. There, the values of coefficients of overloading (degree of exceeding of 


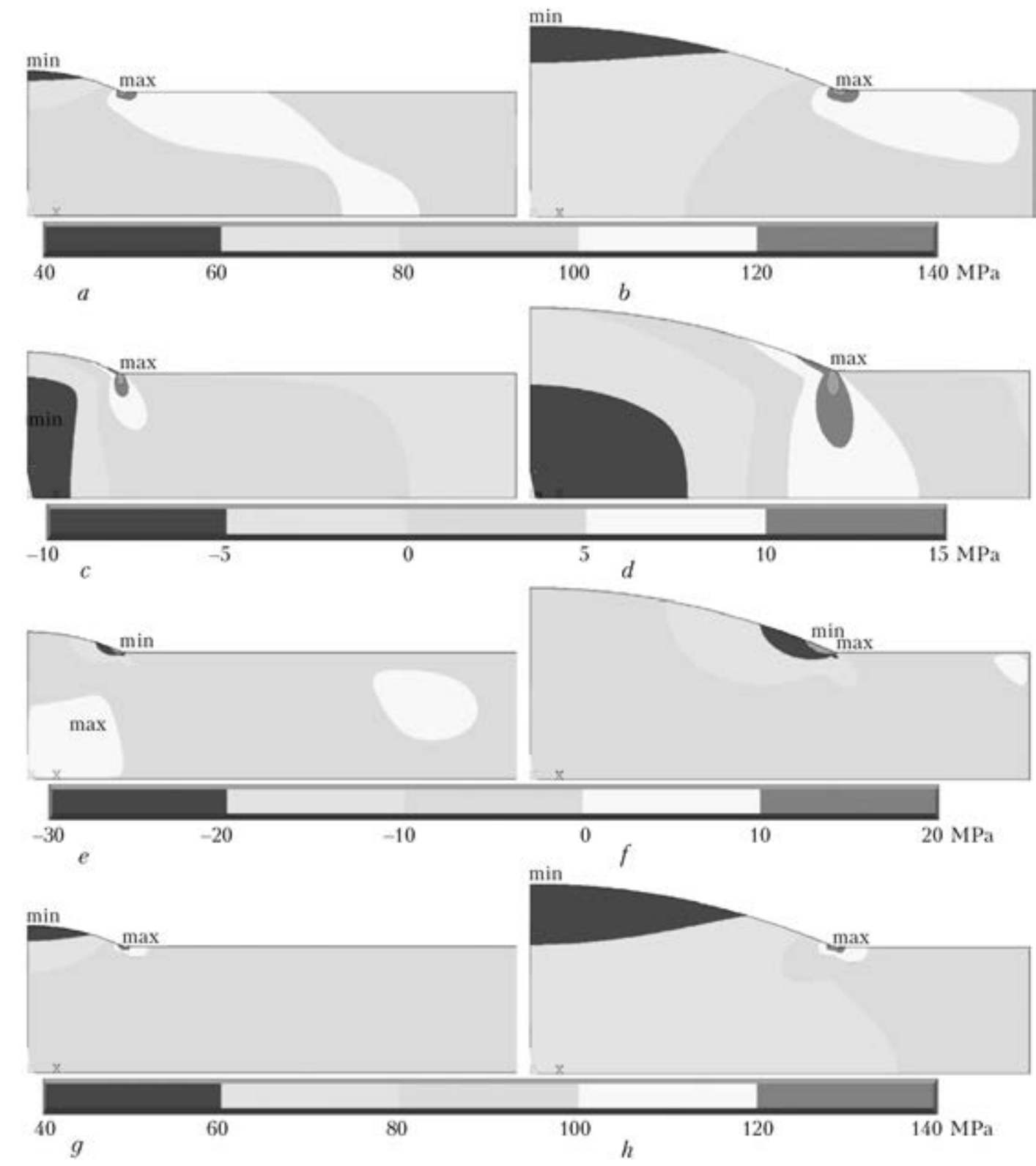

Figure 3. Fields of longitudinal $(a, b)$, transverse $(c, d)$, tangent $(e, f)$ and equivalent $(g, h)$ stresses: $a, c, e, g-$ variant $1 ; b, d, f, h-$ variant 3

maximum stresses over average ones in section) in the first and second sections $\left(\sigma_{\max 1} / \sigma_{\mathrm{av} 1}\right.$ and $\left.\sigma_{\max 2} / \sigma_{\mathrm{av} 2}\right)$ and coefficients of concentration of stresses in sections $3\left(\sigma_{\max 3} / \sigma_{\mathrm{av} 3}\right)$ and 2 in joint C21 $\left(\sigma_{\max 2} / \sigma_{\text {av2 }}\right)$ are also given.

As is seen from Tables, the degree of overloading is little changed with changing the convexity sizes.

In joint C25 in change of reinforcement coefficient $K_{\mathrm{r}}$ (thickness increase in weld zone) from 1.17 to 1.50 (see Table 1 ) the coefficient of overloading by equivalent stresses is remained at the level of 1.13-1.18 in section 1 and 1.07-1.10 in section 2. As is seen, the change does not exceed 3-5\%. Moreover, the comparison of sections 1 and 2 shows that value and nature of distribution of stresses in them are very small differed and here the coefficient of overloading is somewhat higher in section 1 , therefore in further calcula- tions only section 1 will be regarded, and the coefficient of overloading will be taken equal to 1.145 by equivalent stresses.

In section 3 the coefficient of stress concentration $\left(\sigma_{\max 3} / \sigma_{\mathrm{av} 3}\right)$ in change of $K_{\mathrm{r}}=(s+2 a) / s$ from 1.17 up to 1.50 is increased negligibly and remain at the level of about 2 (1.92-2.18).

In joint C21 in $K_{\mathrm{r}}$ change in investigated variants in the ranges of 1.11-1.33 (see Table 2) the coefficient of overloading by equivalent stresses in section 1 is changed proportionally from 1.14 to 1.34 , i.e. it is almost remained equal to coefficient of reinforcement.

In section 2 the coefficient of concentration with $K_{\mathrm{r}}$ growth is increased from 1.43 up to 2.39, and in section 3 it is not almost changed, remaining in the ranges of 1.59-1.70. 

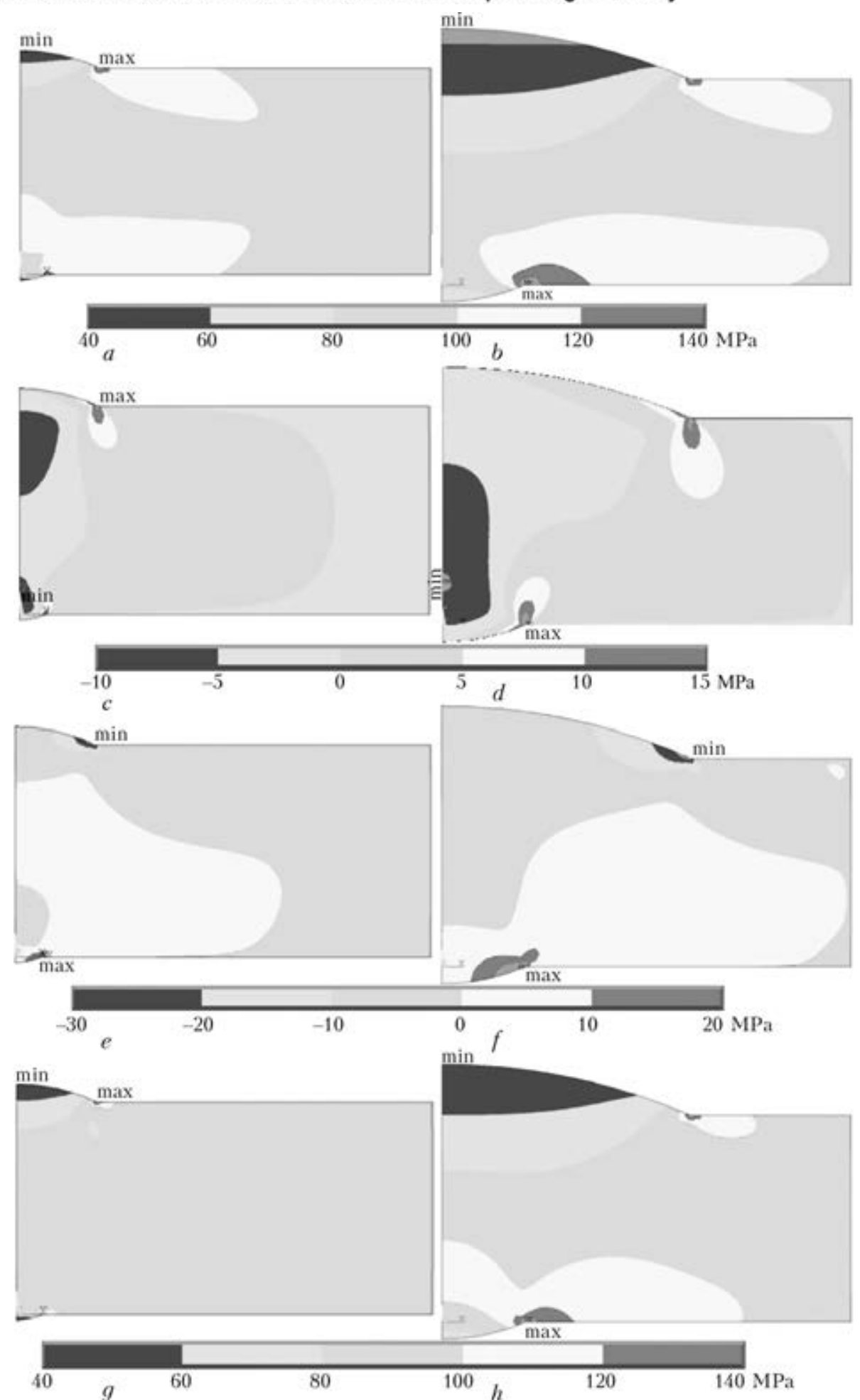

Figure 4. Fields of longitudinal $(a, b)$, transverse $(c, d)$, tangent $(e, f)$ and equivalent $(g, h)$ stresses: $a, c, e, g-$ variant $11 ; b, d, f, h-$ variant 13

In joint $\mathrm{C} 25$ the growth of average and maximum equivalent stresses in section 1 is decreased with increase in height of convexity (Figure 7 , $a$ ), that evidences of principal capability of using convexity to compensate the decrease in strength of weld metal and strength improvement of such a joint during static loads.

In joint C21 the level of maximum stresses in section 1 almost does not depend on the height of convexities, though average stresses are decreased (Figure $7, b$ ), i.e. in the joint of such a type the increase of even static strength due to a growth of convexities is practically impossible. To obtain the dependence of necessary height of convexity in joint C25 on the correlation of strength of weld and base metal, let us introduce the term of relative strength of weld metal (level or coefficient of softening of weld metal, coeffi- 


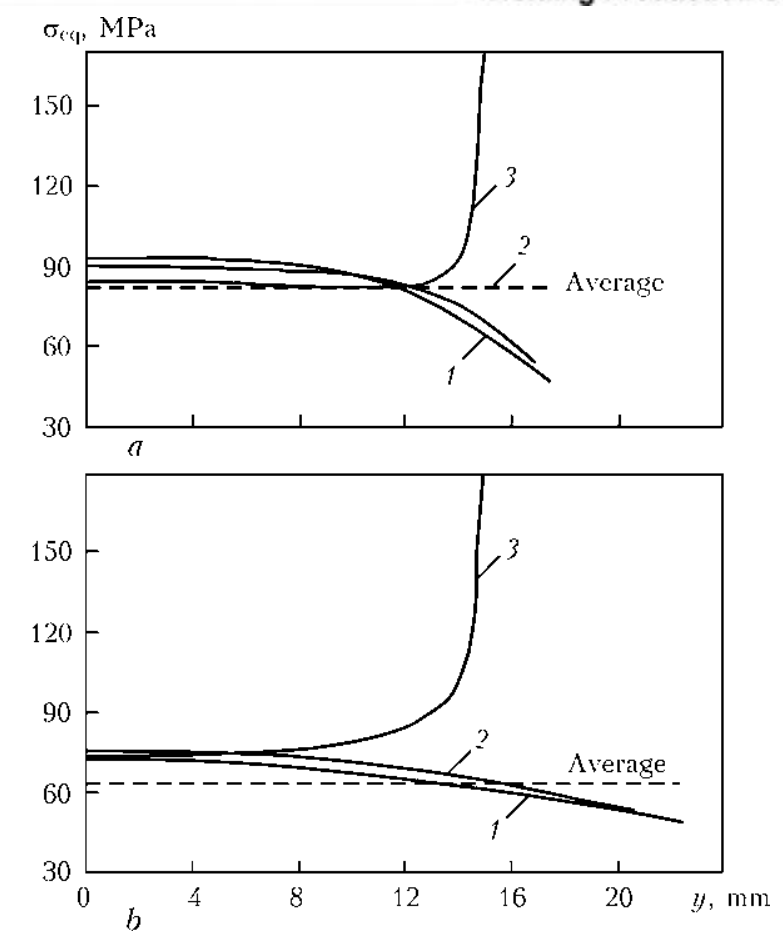

Figure 5. Diagrams of equivalent stresses in sections 1-3 for variants $1(a)$ and $3(b)$

cient of decrease of strength of weld metal) $\kappa_{\mathrm{wm}}=\frac{\left[\sigma_{\mathrm{wm}}\right]}{\left[\sigma_{\mathrm{bm}}\right]}=\frac{\sigma_{\mathrm{ywm}}}{\sigma_{\mathrm{ybm}}}$ and use the condition of equilibrium of the node

$$
\sigma_{\mathrm{av} 1}(s+2 a)=\sigma_{\mathrm{bm}} s
$$

and condition of strength for section 1

$$
\sigma_{\max 1} \leq\left[\sigma_{\mathrm{wm}}\right] \text { or } \kappa_{\mathrm{ovl} 1} \sigma_{\mathrm{av} 1} \leq\left[\sigma_{\mathrm{wm}}\right],
$$

where $\kappa_{\text {ovl1 }}=\sigma_{\max 1} / \sigma_{\text {av }}$ is the coefficient of overloading in section $1 ;\left[\sigma_{\mathrm{wm}}\right]$ and $\sigma_{\mathrm{y} w \mathrm{wm}}$ are the admissible stresses and yield strength of weld metal, respectively; $\left[\sigma_{\mathrm{bm}}\right]$ and $\sigma_{\mathrm{y} \text { bm }}$ are the admissible stresses and yield strength of base metal, respectively.

From the equilibrium equation (1)

$$
\sigma_{\mathrm{av} 1}=\sigma_{\mathrm{bm}} \frac{s}{s+2 a} \text { or } \sigma_{\mathrm{av} 1}=\sigma_{\mathrm{bm}} / K_{\mathrm{r}} \text {, }
$$

where $K_{\mathrm{r}}=\frac{s+2 a}{s} \geq 1$.

It is obvious that in the ultimately loaded state, equation (3) shall be written in the form of $\sigma_{\mathrm{av} 1}=\left[\sigma_{\mathrm{bm}}\right] / K_{\mathrm{r}}$.

Then the condition of strength in section 1 (2) can be written as

$$
K_{\mathrm{ovl1}} \frac{\left[\sigma_{\mathrm{bm}}\right]}{K_{\mathrm{r}}} \leq\left[\sigma_{\mathrm{wm}}\right] \text { or } \frac{\kappa_{\mathrm{ovl} 1} \frac{\left[\sigma_{\mathrm{bm}}\right] \leq\left[\sigma_{\mathrm{wm}}\right]}{s+2 a}}{s},
$$

hence, shall obtain after transformations
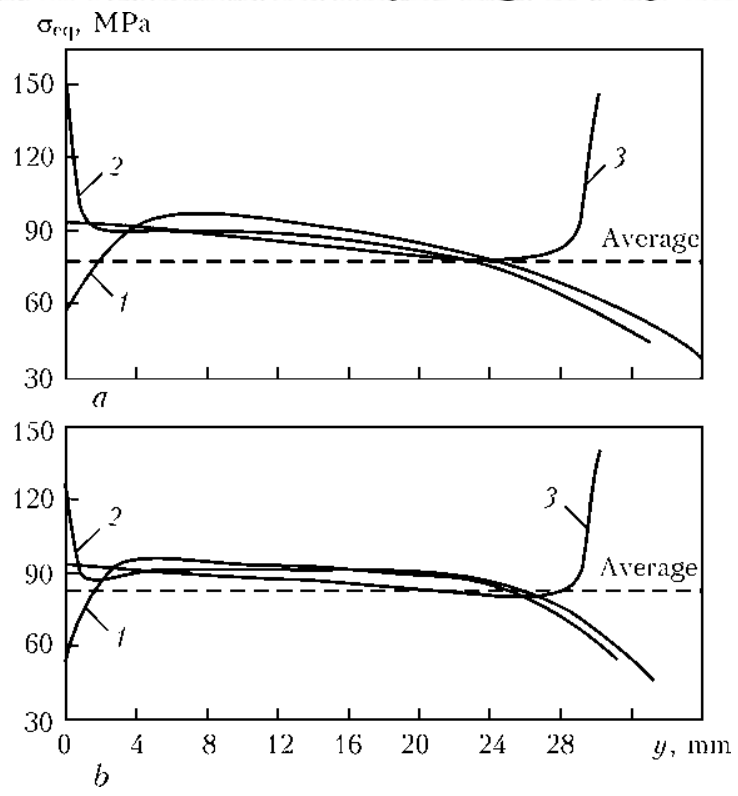

Figure 6. Diagrams of equivalent stresses in sections 1-3 for variants $11(a)$ and $13(b)$

$$
a \geq 0.5 s\left(\frac{\kappa_{\mathrm{ovl}}}{\kappa_{\mathrm{wm}}}-1\right),
$$

or at $K_{\mathrm{ovl}}=1.145 a \geq 0.5 s\left(\frac{1.145}{\kappa_{\mathrm{wm}}}-1\right)$.

Thus, the necessary value of convexity height shall be determined by the degree of uniformity of distribution of stresses in weld metal $\left(\kappa_{\text {ovl }} \geq\right.$ $\geq 1)$ and decrease of strength of weld metal as compared to the base metal $\left(\kappa_{\mathrm{wm}} \leq 1\right)$. Thus, at $\kappa_{\mathrm{ovl}}=1.145$ and decrease in strength of weld metal by $20 \%$, i.e. $\kappa_{\mathrm{wm}}=0.8$ for the thickness of $30 \mathrm{~mm}$, the necessary minimum height of convexity will amount to $6.5 \mathrm{~mm}$, and at decrease of strength of weld metal by $10 \%$ it will be $4 \mathrm{~mm}$.

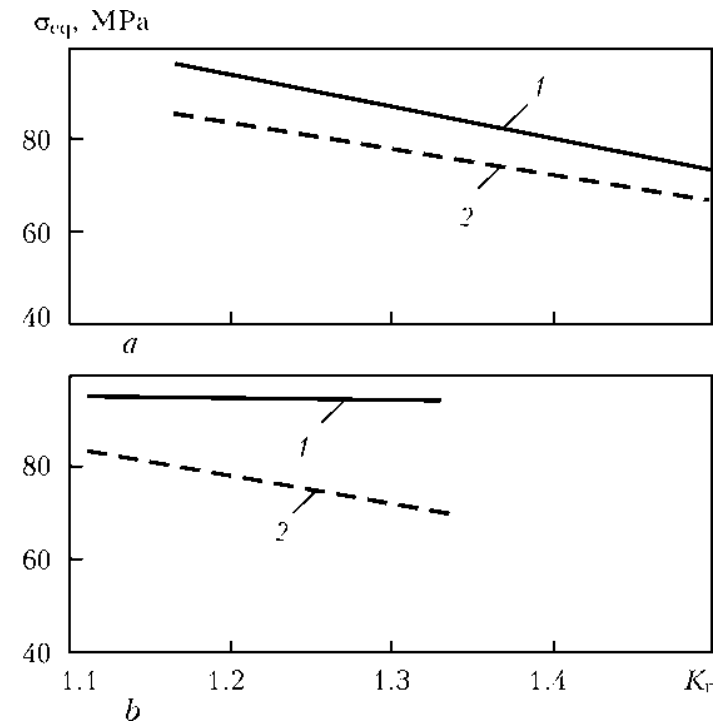

Figure 7. Dependence of maximum (1) and average (2) equivalent stresses in section 1 for joints C25 $(a)$ and C21 (b) on coefficient of weld reinforcement 
Welding Production Chair of Admiral Makarov National Shipbuilding University

Table 3. Equivalent stresses in sections $1-3$ in the investigated variants of joints of C25 type

\begin{tabular}{||c|c|c|c|c|c|c|c|c|c|c||}
\hline \hline Number of variant & $\sigma_{\max 1}$ & $\sigma_{\mathrm{av} 1}$ & $\sigma_{\max 2}$ & $\sigma_{\mathrm{av} 2}$ & $\sigma_{\min 3}$ & $\sigma_{\max 3}$ & $\sigma_{\mathrm{av} 3}$ & $\sigma_{\max 1} / \sigma_{\mathrm{av} 1}$ & $\sigma_{\max 2} / \sigma_{\mathrm{av} 2}$ & $\sigma_{\max 3} / \sigma_{\mathrm{av} 3}$ \\
\hline 1 & 93 & 82 & 89 & 83 & 84 & 170 & 85 & 1.13 & 1.07 & 2.0 \\
\hline 2 & 87 & 74 & 84 & 77 & 77 & 183 & 83 & 1.18 & 1.09 & 2.2 \\
\hline 3 & 72 & 64 & 75 & 68 & 73 & 188 & 81 & 1.13 & 1.10 & 2.3 \\
\hline 4 & 92 & 82 & 89 & 83 & 83 & 167 & 85 & 1.12 & 1.07 & 2.0 \\
\hline 5 & 86 & 74 & 83 & 76 & 77 & 180 & 83 & 1.16 & 1.09 & 2.2 \\
\hline 6 & 72 & 63 & 75 & 68 & 73 & 186 & 81 & 1.14 & 1.10 & 2.3 \\
\hline 7 & 91 & 81 & 88 & 82 & 82 & 160 & 85 & 1.12 & 1.07 & 1.9 \\
\hline 8 & 84 & 73 & 82 & 76 & 77 & 174 & 83 & 1.15 & 1.08 & 2.1 \\
\hline 9 & 70 & 63 & 74 & 68 & 74 & 182 & 81 & 1.11 & 1.09 & 2.2 \\
\hline $\begin{array}{c}\text { Average value for } \\
\text { all the variants }\end{array}$ & - & - & - & - & - & - & - & 1.14 & 1.08 & 2.13 \\
\hline
\end{tabular}

Table 4. Equivalent stresses in sections $1-3$ in the investigated variants of joints of C21 type

\begin{tabular}{||c|c|c|c|c|c|c|c|c|c|c||}
\hline \hline Number of variant & $\sigma_{\max 1}$ & $\sigma_{\mathrm{av} 1}$ & $\sigma_{\max 2}$ & $\sigma_{\mathrm{av} 2}$ & $\sigma_{\min 3}$ & $\sigma_{\max 3}$ & $\sigma_{\mathrm{av} 3}$ & $\sigma_{\max 1} / \sigma_{\mathrm{av} 1}$ & $\sigma_{\max 2} / \sigma_{\mathrm{av} 2}$ & $\sigma_{\max 3} / \sigma_{\mathrm{av} 3}$ \\
\hline 1 & 95 & 83 & 123 & 86 & 80 & 141 & 88 & 1.14 & 1.43 & 1.60 \\
\hline 2 & 97 & 78 & 150 & 81 & 78 & 146 & 87 & 1.24 & 1.85 & 1.68 \\
\hline 3 & 95 & 71 & 177 & 74 & 77 & 148 & 87 & 1.34 & 2.39 & 1.70 \\
\hline 4 & 95 & 83 & 126 & 86 & 80 & 140 & 88 & 1.14 & 1.47 & 1.59 \\
\hline 5 & 97 & 78 & 150 & 81 & 78 & 146 & 87 & 1.24 & 1.85 & 1.68 \\
\hline 6 & 94 & 71 & 176 & 74 & 77 & 147 & 87 & 1.32 & 2.38 & 1.69 \\
\hline 7 & 95 & 83 & 126 & 86 & 81 & 136 & 88 & 1.14 & 1.47 & 1.55 \\
\hline 8 & 96 & 78 & 150 & 81 & 78 & 143 & 87 & 1.23 & 1.85 & 1.64 \\
\hline 9 & 94 & 70 & 175 & 73 & 77 & 145 & 87 & 1.34 & 2.40 & 1.67 \\
\hline $\begin{array}{c}\text { Average value for } \\
\text { all the variants }\end{array}$ & - & - & - & - & - & - & - & - & - & 1.64 \\
\hline
\end{tabular}

\section{Conclusions}

1. At change of sizes of convexity in rather wide range the coefficient of concentration of equivalent stresses in the sites of transition from base to deposited metal is changed in the ranges of 1.9-2.3 in joint $\mathrm{C} 25 ; 1.55-1.7$ from the outer side and 1.45-2.40 from the back side of joint $\mathrm{C} 21$.

2. Presence of convexity in the symmetric joint C25 somewhat decreases the level of tensile and equivalent stresses inside the weld metal, that provides a possibility to compensate the decrease of its strength as compared to the base metal, but this decrease is not proportional to the increase of section area.

3. The expression was obtained, which allows calculating the necessary value of convexity in joint C25 at the known level of decrease of deposited strength metal as compared to the base one.

4. Presence of convexities and their size in non-symmetric joint C21 almost does not influence the level of maximum equivalent stresses in the section along the weld axis, therefore, it is impossible to compensate the decreased strength of weld metal by increase of convexities.
2. GOST 8713-79: Submerged-arc welding. Welded joints. Main types, structural elements and sizes. Publ. 2005. Moscow: Standart.

3. GOST 14771-76: Gas-shielded arc welding. Main types, structural elements and sizes. Publ. 2000. Moscow: Standart.

4. GOST 2601-84: Welding of metals. Terms and definitions of basic concepts. Publ. 1995. Moscow: Standart.

5. DSTU 3761.3-98: Welding and related processes. $\mathrm{Pt}$ 3: Welding of metals: joints and welds, technology, materials and equipment. Terms and definitions. Publ. 1999. Kyiv: GKSMSU.

6. Nikolaev, G.A., Kurkin, S.A., Vinokurov, V.A. (1982) Welded structures. Strength of welded joints and deformation of structures. Moscow: Vysshaya Shkola.

7. Nikolaev, G.A., Kurkin, S.A., Vinokurov, V.A. (1971) Calculation, design and fabrication of welded structures. Moscow: Vysshaya Shkola.

8. Karkhin, V.A. (1985) Influence of weld shape on stress distribution in tensile of large thickness butt joints. Avtomatich. Svarka, 9, 25-28.

9. Stakanov, V.I., Kostylev, V.I., Rybin, Yu.I. (1987) About calculation of stress concentration coefficient for butt welded joints. Ibid., 11, 19-23.

10. Karkhin, V.A., Kostylev, V.I., Stakanov, V.I. (1988) Influence of geometric parameters of butt, $\mathrm{T}$ - and cruciform joints on stress concentration coefficient. Ibid., 3, 6-11.

11. Pustovit, A.I., Voronin, S.A., Yushchenko, K.A. (1987) Influence of stress concentration on strength of martensitic steel welded joints. Ibid., 9, 1-3.

12. Makhnenko, V.I. (2006) Resource of safety service of welded joints and assemblies of modern structures. Kiev: Naukova Dumka.

1. GOST 5264-80: Manual arc welding. Welded joints. Main types, structural elements and sizes. Publ. 1993. Moscow: Standart. 